\title{
Çim Peleti Üretiminde Kalıp Delik Çapı ve Nem İçeriğinin Üretim Parametreleri ve Pelet Fiziksel Özelliklerine Etkisi
}

\author{
Hasan Yılmaz*iD Mehmet Topakcı Murad Çanakcı iD Davut Karayel
}

\begin{abstract}
Akdeniz Üniversitesi, Ziraat Fakültesi, Tarım Makinaları ve Teknolojileri Mühendisliği Bölümü, Konyaaltı/ANTALYA
*Sorumlu yazar: hasanyilmaz@akdeniz.edu.tr
\end{abstract}

Geliş Tarihi: 06.05.2020

Kabul Tarihi: 27.05.2021

$\ddot{\mathbf{O z}}$

Bu çalışmada peyzaj alanlarında ortaya çıkan çim biçme artıklarının pelet hammaddesi olarak kullanım olanakları araştırılmıştır. Peletleme işleminde temel değişkenler içerisinde yer alan peletleme nemi ve pelet çapının, pelet üretim koşulları ve pelet fiziksel özelliklerine etkisi belirlenmiş ve ilgili standartlara uygunluğu incelenmiştir. Bu amaçla, denemelerde \%14 ve \%17 olmak üzere iki farklı peletleme neminde ve $6 \mathrm{~mm}$ ve $8 \mathrm{~mm}$ olmak üzerinde iki farklı kalıp delik çapında peletler (P6-14; P6-17; P8-14; P8-17) üretilmiştir. Peletlere ait fiziksel özellikler kapsamında; nem içeriği, yığın yoğunluğu, parça yoğunluğu, dayanıklılık direnci ve darbe direnci değerleri belirlenmiştir. İşletme değerleri açısından önemli olan üretim sırasındaki enerji tüketimi değerleri ölçülmüş ve üretim kapasitesi değerleri hesaplanmıştır. Araştırma bulgularına göre peletleme nem ve pelet çapının artışı üretim kapasitesini artırmakta, enerji tüketimini düşürmekle birlikte pelet fiziksel özelliklerini olumsuz yönde etkilemektedir. Pelet parça yoğunluğu ve yığın yoğunluğu değerleri, pelet çapının ve peletleme neminin artmasıyla azalmıştır. En yüksek parça ve yığın yoğunluğu değerleri P6-14 peletlerinde $1024.11 \mathrm{~kg} / \mathrm{m}^{3}$ ve $624.07 \mathrm{~kg} / \mathrm{m}^{3}$, en düşük parça ve yığın yoğunluğu değerleri $P 8-17$ peletlerinde $787.06 \mathrm{~kg} / \mathrm{m}^{3}$ ve $479.29 \mathrm{~kg} / \mathrm{m}^{3}$ olarak hesaplanmıştır. En yüksek pelet dayanıklılık direnci değerine sahip olan P6-14 peletlerinin dayanıklılık direnci değeri \%95.97 ile standart değerin ( $\geq \% 97.5)$ altındadır. Çalışma sonunda, çim biçme artıklarının düşük nem içeriğinde peletlenmesi veya karışım materyali olarak peletlenmesi güç olan biyokütle kaynaklarıyla kullanılabileceği sonucuna varılmıştır.

Anahtar Kelimeler: Pelet, pelet kalıbı, biyokütle, pelet fiziksel özellikleri, çim biçme artı̆̆ı

\section{The Effects of Die Hole Diameter and Pelletizing Moisture on Production Parameters and Physical Properties of Grass Pellets}

\section{Abstract}

In this study, alternative pellet raw material usage possibilities of lawn mowing residues emerging from landscape areas were investigated During pellet production, energy consumption and production capacity were measured. Regarding to pellet physical properties, moisture content (MC), bulk density (BD), particle density (PD), pellet durability index (PDI) and impact resistance (IR) values were determined. For this purpose, $6 \mathrm{~mm}$ and $8 \mathrm{~mm}$ diameter pellets were obtained at $14 \%$ and $17 \%$ pelletizing moisture (P6-14, P6-17, P8-14, P8-17). Although the increase in pelleting moisture and pellet diameter increased the production capacity and decreased energy consumption, it negatively affected the pellet physical properties. Increasing the diameter value of pellets with 6 and $8 \mathrm{~mm}$ diameter at the same moisture content decreased the pellet physical qualities. PDI and BD values decreased with increasing pellet diameter and pelletizing moisture. The highest PD and BD values were calculated as $1024.11 \mathrm{~kg} / \mathrm{m}^{3}$ and $624.07 \mathrm{~kg} / \mathrm{m}^{3}$ for P6-14 pellets, and lowest PD and BD values were 787.06 $\mathrm{kg} / \mathrm{m}^{3}$ and $479.29 \mathrm{~kg} / \mathrm{m}^{3}$ for P8-17 pellets. The highest PDI values obtained with P6-14 pellets as $95.97 \%$, which is below the standard value ( $\geq 97.5 \%)$. At the end of the study, it was concluded that lawn mowing residues should be pelleted with low moisture pelleting or use as mixture material for biomass sources that are difficult to pelletize.

Keywords: Pellet, pellet die, biomass, pelet physical properties, grass, lawn mowing residue

\section{Giriş}

Isıl ihtiyaçların karşılanması için fosil yakıtların kullanımına bağlı yüksek emisyon gazı salınımı toplumun yaşam kalitesini, biyoçeşitliliği ve doğal kaynakları olumsuz yönde etkilemektedir (Niedziółka et al. 2015). Fosil yakıtlar yerine kullanılabilecek alternatif enerji kaynaklarından birisi biyokütle enerjisidir. Biyokütle kaynakları genellikle orman endüstrisi artıkları, peyzaj artıkları, tarımsal artıklar, budama artıkları ve şehir artıklarından oluşmaktadır. Kaba formda düşük yoğunluk 
ve yüksek nem içeriğine sahip olan biyokütle kaynakları, taşıma, depolama faaliyetlerinin iyileştirilmesi ve etkin bir şekilde yakılması için sıkıştırma işlemine tabi tutulmaktadır (Hiloidhari et al. 2014). Yüksek nem içeriğine sahip, düşük yoğunluklu ve heterojen yapıda olan biyokütle kaynaklarının sıkıştırılmasında kullanılan yöntemlerden biri peletleme işlemidir (Ungureanu et al. 2018). Peletleme işleminde, biyokütle kaynakları fiziksel özellikleri iyileştirilmiş ve otomatik yakma sistemlerinde verimli bir biçimde yakılabilen katı yakıta dönüştürülmektedir (Carroll and Finnan 2012). Peletler, biyokütle kaynağının parçalanıp öğütülmesi, öğütülen materyalin uygun koşullar altında konik deliklere sahip pelet kalıbı ve sıkıştırma silindirlerinden oluşan pelet makineleri ile basınç altında sıkıştırılması ile üretilmektedir. Peletleme işlemine hammadde kaynaklı birçok faktör etki etmektedir. Başlıca faktörler; hammaddenin parçacık boyut dağılımı (Kirsten et al. 2016), peletleme nemi (Garcia-Maraver et al. 2015), materyal karışım oranı (Niedziółka et al. 2015) ve sıcak buhar uygulaması (Filbakk et al. 2011) olarak sıralanabilir. Peletleme işlemine ve pelet kalitesine, hammadde ile birlikte pelet makinalarının temel parçaları da etki etmektedir. Peletleme işlemine etkili başlıca makine parçaları kalıp ve silindirlerdir (Amiri et al. 2019). Mevcut koşullarda sürdürülebilir pelet üretimi için hammadde tedarikinin sağlanması, hammadde karakteristiklerinin belirlenmesi ve hammadde özellikleriyle peletleme makinesi temel bileşenlerinin uyumlu olması gerekmektedir (Yilmaz et al. 2020). İdeal koşullarda üretilen peletler yüksek fiziksel dayanım ve yüksek yoğunluk değeri ile etkin taşıma ve depolama etkinliğine sahip olmaktadır (Mani et al. 2006; Niedziółka et al. 2015).

Pelet kalıpları, hammaddenin sıkışarak pelet formuna dönüştüğü daralan konik kesitli deliklere sahiptir. Konik deliklerin çıkış çapları genellikle 6,8 veya $10 \mathrm{~mm}$ 'dir ve farklı çaptaki pelet üretimi için pelet makinesinde farklı delik çaplarına sahip kalıplar kullanılabilmektedir (Tumuluru 2014; Amiri et al. 2019). Avrupa Pelet Konseyi tarafindan belirlenen standartlara göre pelet çaplarının, kullanım yerine bağlı olarak $6( \pm 1)$ veya $8( \pm 1) \mathrm{mm}$ çapında olması gerektiğini bildirilmiştir (ENplus 2015). Bunun yanında otsu yapıda hammaddeden üretilen peletlerin dahil edildiği EN ISO 17225-6 standardında pelet çaplarının $6 \mathrm{~mm} \leq \mathrm{D} \leq 25 \mathrm{~mm}( \pm 1)$ değerinde olabileceği bildirilmiştir (EN ISO 17225-6, 2014). Pelet çaplarıyla ilgili, ev tipi pelet yakma sistemlerinde pelet çapının genellikle $6 \mathrm{~mm}$ olması tavsiye edilirken, endüstriyel ölçekli yakma sistemlerinde $8 \mathrm{~mm}$ çapında pelet kullanımı yaygındır (Anonim; Anonim (a); Anonim (b); Anonim (c); Anonim (d); Anonim (e); Anonim (f)).

Biyokütle peletleri genellikle orman endüstrisi artıklarından üretilmektedir. Son yıllarda, evsel ve endüstriyel alanlarda pelet kullanımının artması nedeniyle alternatif hammadde ihtiyacı doğmuştur (Agar et al. 2018; Pradhan et al. 2018). Yapılan çalışmalarda pelet hammaddesi potansiyeli bulunan mısır sapı, mısır koçanı, buğday samanı, kanola, arpa gibi birçok bitkisel artık değişken koşullarda peletlenerek pelet üretim koşulları ve pelet fiziksel özellikleri incelenmiştir (Adapa et al. 2009; Theerarattananoon et al. 2011; Emami et al. 2014; Tumuluru 2014; Wongsiriamnuay and Tippayawong 2015; Azócar et al. 2019). Çeşitli tarımsal artıkların yanı sıra, kentsel peyzaj alanlarında belirli periyotlarda yapılan bakım ve biçim işlemleri sonucu ortaya çıkan bitkisel artıklar da biyokütle kaynağı olarak önemli bir potansiyele sahiptir.

Çim bitkisi; belediyeler, üniversite kampüsleri, sosyal ve sportif alanlarda peyzaj düzenlemeleri kapsamında yetiştirilen bir yerörtücü bitkidir. Çim alanları, sık bir halde gelişerek homojen bir görünüşe sahip olan, toprak üstünü örten, belirli periyotlarda biçilerek kısa tutulan bir bitkidir (Orçun 1979). Çim alanlarında biçim işlemleri sonrası önemli miktarda artık ortaya çıkmaktadır. Akdeniz Üniversitesi Kampus alanları için yapılan bir çalışmada toplam $648410 \mathrm{~m}^{2}$ çim alanından yılda toplam 185.3 ton kuru çim artığı çıktığı belirlenmiştir. Bu değerler ile kuru çim artığ1 potansiyeli yaklaş1k $0.3 \mathrm{~kg} / \mathrm{m}^{2}$ olarak hesaplanabilir. Biyokütle kaynağ 1 olarak enerji kaynağ potansiyeli bulunan çim bitkisi, gazlaştırma, yanma ve termokimyasal özelliklerinin belirlenmesi amaciyla pelet formunda (Chandrasekaran et al. 2013; Diken 2017; Platace et al. 2017) ve biyogaz hammaddesi olarak (Aghayev 2019) kullanılmıştır. Çim bitkisinin pelet formunda kullanımına ait bazı çalışmalar bulunmaktadır Ancak çim peletleme işlemlerinde, üretim koşullarındaki değişkenler ve peletlerin fiziksel özelliklerinin incelenmesi üzerine yapılan çalışmalar sınırlı kalmaktadır.

$\mathrm{Bu}$ çalışmada, çim alanlarında bakım işlemleri sırasında biçim sonrası ortaya çıkan çim artıklarının peletlenmesi sırasında peletleme neminin ve pelet çapının pelet üretim parametreleri ile pelet fiziksel özelliklerine etkisi araştırılmıştır. 


\section{Materyal ve Yöntem}

Çalışmada, Akdeniz Üniversitesi Kampüsü'nde yer alan peyzaj alanlarından biçilen çimler kullanılmıştır. Çimlerin biçim sırasında ölçülen nem değeri \% 81.2'dir. Peletleme işleminden önce çim biçme artıkları beton zemin üzerinde, güneş 1şı̆̆ altında, düzenli aralıklarla karıştırılarak 4-5 gün boyunca doğal yöntem ile kurutulmuştur. Kurutulan materyaller $2 \mathrm{~mm}$ elek delik çapına sahip, traktör kuyruk milinden hareketli bir çekiçli değirmen ile öğütülmüştür.

Kurutma ve öğütme işlemi sonrasında \%9-10 düzeyinde olan nem içeriği kontrollü olarak \%13-14 ve \%17-18 düzeylerine getirilmiştir. Nemlendirme işleminde, kuru materyale eklenecek su miktarının belirlenmesinde aşağıdaki eşitlik (1) kullanılmıştır.

$Q=W_{i}\left(M_{f}-M_{i}\right) /\left(100-M_{f}\right)$

Eşitlikte, $Q$ : Eklenecek su miktarı (g); $W_{i}$ : Materyalin ilk ağırlı̆̆ $(\mathrm{g}) ; M_{i}$ : Materyalin ilk nem içeriği $(\%) ; M_{f}$ : Materyalin istenen nem içeriği (\%)

Nemlendirme işleminde kuru materyal kanatlı bir karıştırıcı içine boşaltılmış, miktarı hesaplanan su püskürülerek 10 dakika boyunca karıştırılmıştır. Nemlendirilen materyaller 2 gün boyunca ağzı kapalı torbalarda saklanarak nemin eşit oranda materyal içinde dağılım göstermesi sağlanmıştır.

Ögütülmüsş materyalin parçacık boyut dağılımının belirlenmesinde $0.125,0.25,0.5,1,1.7$, 2.36 ve $3 \mathrm{~mm}$ delik çaplarında eleklerin bulunduğu elek analiz seti kullanılmıştır. Ögü̈tülmüş materyalin ortalama geometrik çap değeri ASAE S319.3 (2003) standardına göre aşağıdaki eşitlik (2) yardımıla hesaplanmıştır.

$\mathrm{d}_{\mathrm{gw}}=\log ^{-1}\left[\sum_{\mathrm{i}=1}^{\mathrm{n}}\left(\mathrm{w}_{\mathrm{i}} \log (\mathrm{di})\right) / \sum_{\mathrm{i}=1}^{\mathrm{n}} \mathrm{w}_{\mathrm{i}}\right]$

Eşitlikte, $d_{g w}$ : Ortalama geometrik çap $(\mathrm{mm}) ; w_{i}$ : Elekte biriken materyal kütlesi $(\mathrm{g})$; di: Elek açıklı̆̆ $(\mathrm{mm}) ; n$ : Elek sayısı

Elek delik çapı $2 \mathrm{~mm}$ olan çekiçli değirmende ögütülen çim materyalinin parçacık boyut dağılımı Şekil 1'de yer almaktadır.

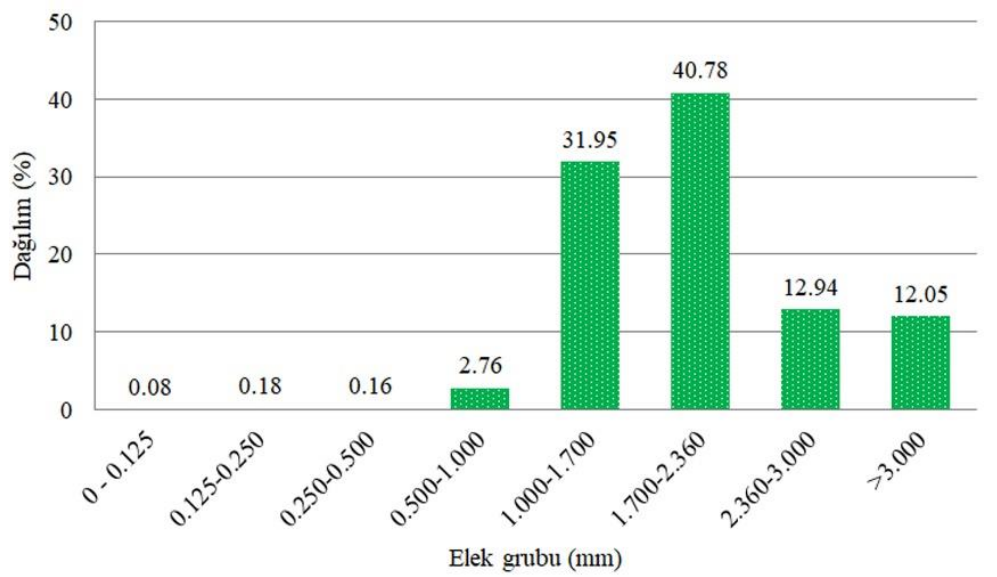

Şekil 1. Öğütülmüş çim biçme artıklarının parçacık boyut dağılımı

Öğ̈̈ülmüş çim materyalinin parçacık boyut dağılımında $1 \mathrm{~mm}$ 'den büyük partiküller toplam partiküllerin \%98'ini oluşturmaktadır. Parçacık boyut analizine göre $2 \mathrm{~mm}$ elek delik çapında öğütülmüş çim artıklarının ortalama geometrik çap değeri $0.503 \mathrm{~mm}$ olarak hesaplanmıştır. Biçilmiş halde kaba formda ve öğütülmüş formdaki çim biçme artıklarının yığın yoğunluğu değerleri sırasıyla $38.46 \mathrm{~kg} / \mathrm{m}^{3}$ ve $281.73 \mathrm{~kg} / \mathrm{m}^{3}$ olarak belirlenmiştir. Öğ̈üülmüş çim biçme artıklarının nem içerikleri ve pelet çaplarına göre materyal gruplarının belirlendiği deneme planı Çizelge 1'de yer almaktadır.

Çim materyalinin fiziksel özellikleri ve deneme planı Çizelge 1'de yer almaktadır. 
Çizelge 1. Peletleme değiş̧kenlerine göre oluşturulan deneme planı

\begin{tabular}{cccc}
\hline \multirow{2}{*}{ Materyal } & $\begin{array}{c}\text { Pelet çap1 } \\
(\mathrm{mm})\end{array}$ & $\begin{array}{c}\text { Nem içeriği } \\
(\%)\end{array}$ & Pelet kodu \\
\hline \multirow{2}{*}{ Çim } & 6 & 14.35 & P6-14 \\
\cline { 2 - 4 } & \multirow{2}{*}{8} & 17.42 & P6-17 \\
\cline { 2 - 4 } & & 14.24 & P8-14 \\
\hline
\end{tabular}

Peletleme işlemi, yarı endüstriyel, otomatik beslemeli, peletleme ünitesi motor gücü $7.5 \mathrm{~kW}$ olan bir peletleme sistemi ile yapılmıştır. Peletleme sistemi bileşenleri ve pelet üretimi sırasında kullanılan pelet kalıplarının kesit görünümleri Şekil 2'de verilmiştir.

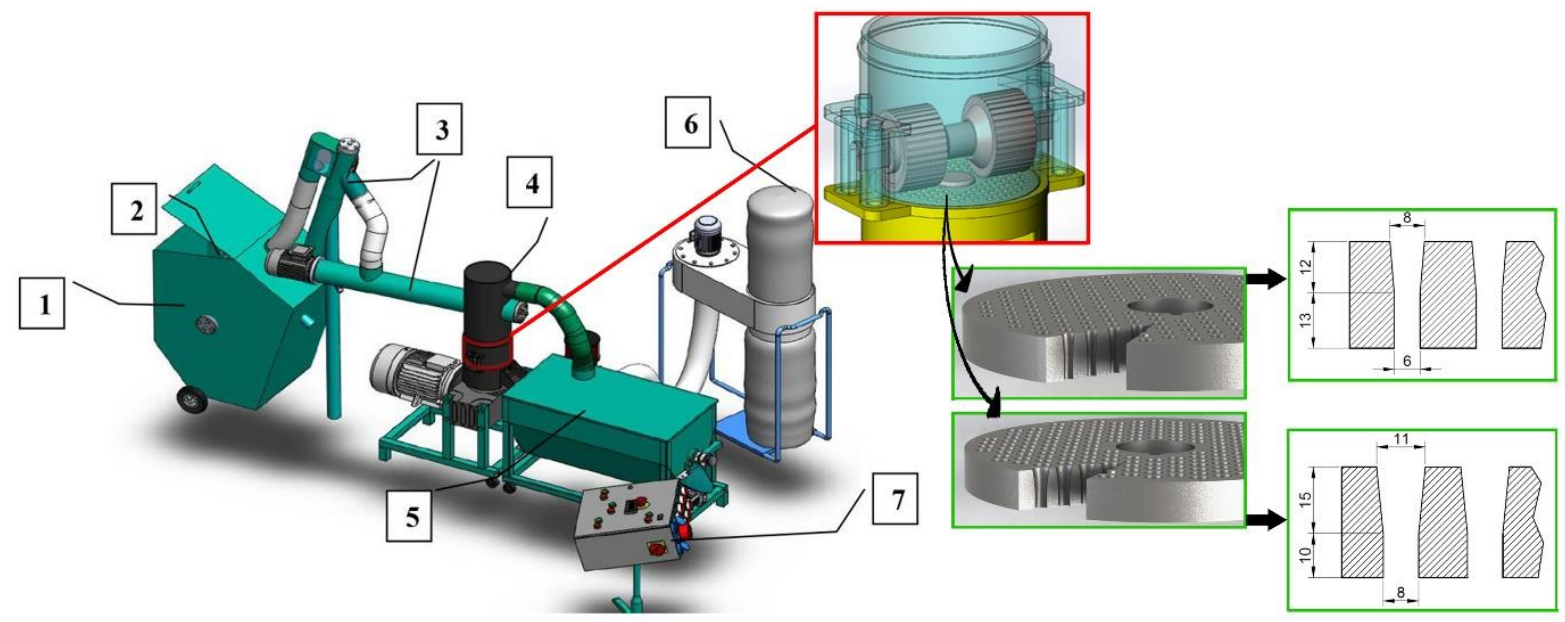

Şekil 2. Denemelerde kullanılan peletleme sistemi ve pelet kalıbı ölçüleri

Peletleme sistemi, 1) Hammadde deposu, 2) Karıştırıc1, 3) İletim helezonları, 4) Peletleme ünitesi, 5) Soğutucu, 6) Aspiratör, 7) Kontrol paneli bileşenlerinden oluşmaktadır.

Pelet üretim kapasitesi, pelet üretiminin rejime girdiği sirada $60 \mathrm{~s}$ boyunca üretilen peletler tartılarak $\mathrm{kg} / \mathrm{h}$ olarak hesaplanmıştır. Pelet üretimi sırasında peletleme sisteminin elektrik enerjisi tüketimi Chauvin Arnoux CA 8332B 3 fazlı portatif enerji analizörü ile ölçülmüştür. Değişken parametrelerle pelet üretiminin eşit koşullar altında yapılabilmesi için, pelet üretimi ve peletleme sistemi elektrik motoru akım değeri anlık olarak gözlemlenerek 12-13 Amper düzeyinde sabit tutulmuştur. Pelet kalıbı sıcaklığının ölçümünde Testo 110 sıcaklık ölçüm cihazı ve yüzey sıcaklığı ölçüm probu kullanılmıştır.

Pelet fiziksel kaliteleri ile ilgili olarak pelet nemi, pelet parça yoğunluğu, pelet yığın yoğunluğu, dayanıklılık direnci ve darbe direnci testleri gerçekleştirilmiştir.

Peletler ve hammaddenin nem içeriği $105^{\circ} \mathrm{C}$ 'de $24 \mathrm{~h}$ kurutulması ile yaş bazda hesaplanmıştır (ASTM E871-82 2019). Pelet parça yoğunluğu ASAE S269.4 (2001) standardına göre 80-100 g peletin boy, çap ve kütlelerinin ölçülmesiyle $\mathrm{kg} / \mathrm{m}^{3}$ olarak hesaplanmıştır. Peletlerin ve hammaddenin yığın yoğunluğu EN 15103 (2009) standardına göre, 5 litre silindirik kap içerisinde doldurulan ürünün tartılması yoluyla $\mathrm{kg} / \mathrm{m}^{3}$ olarak hesaplanmıştır.

Pelet dayanıklılık direnci EN 15210-1 (2009) standardına göre imal edilmiş dayanıklılık test cihazı ile gerçekleştirilmiştir. Cihaz bölmelerine konulan $500 \mathrm{~g}$ pelet 10 dakika boyunca döndürülmüştür. Test sonrasında parçalanan peletler tartılarak ağırlık kaybı \% olarak hesaplanmıştır.

Peletlerin kırılma dirençlerinin belirlenmesi, rastgele seçilen 10 adet peletin 1.85 m yüksekten sert zemine $4 \mathrm{kez}$ düşürülmesi yoluyla gerçekleştirilmiştir. Test sonrasında kırılan peletler $3.15 \mathrm{~mm}$ elekten geçirilerek elek altında kalan parçalar kayıp olarak değerlendirilmiştir. Pelet darbe direnci değeri test öncesi ve test sonrası kütle kaybına bağlı \% olarak hesaplanmıştır (Kaliyan and Vance Morey 2009).

Yapılan testlerin her biri üç tekerrürlü gerçekleştirilmiştir. Elde edilen verilere SPSS programı ile varyans analizi ve Duncan çoklu karşılaştırma testi uygulanmıştır. Ayrıca, pelet fiziksel 
özelliklerinden nem içeriği, yığın yoğunluğu ve dayanıklılık direnci değerleri, odunsu olmayan hammaddelerden üretilen peletleri kapsayan EN ISO 17225-6 standardına göre değerlendirilmiştir.

\section{Bulgular ve Tartışma}

Çalışmada, 6 ve $8 \mathrm{~mm}$ çapında ve $\% 14$ ve $\% 17$ peletleme nemlerinde, üretilen çim artığ peletlerine ait görünümler Şekil 3'de yer almaktadır.

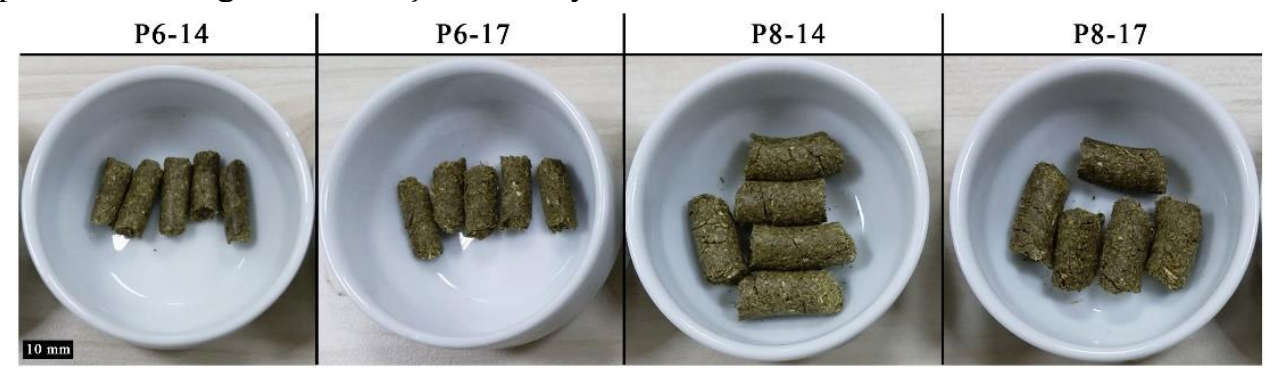

Şekil 3. Çalışmada üretilen çim biçme artığı peletleri

Üretilen peletler incelendiğinde, \%17 peletleme nemindeki peletlerin \%14 peletleme nemindeki peletlere göre daha gevşek yapıda olduğu söylenebilir. Benzer şekilde aynı peletleme nem içeriğinde $8 \mathrm{~mm}$ çapındaki peletler, $6 \mathrm{~mm}$ çapındaki peletlere göre silindirik yapılarını kaybetme eğilimdedirler. Görsel açıdan değerlendirildiğinde P6-14 peletlerinin daha düzgün silindirik yapıda olduğu ortaya çıkmaktadır (Şekil 3).

Farklı nem içeriklerindeki çim biçme artıklarından farklı çaplarda pelet elde edilmesi işlemi sırasında üretim kapasitesi, enerji tüketimi, özgül enerji tüketimi ve pelet kalıbı sıcaklığı değişimleri Şekil 4'de yer almaktadır.

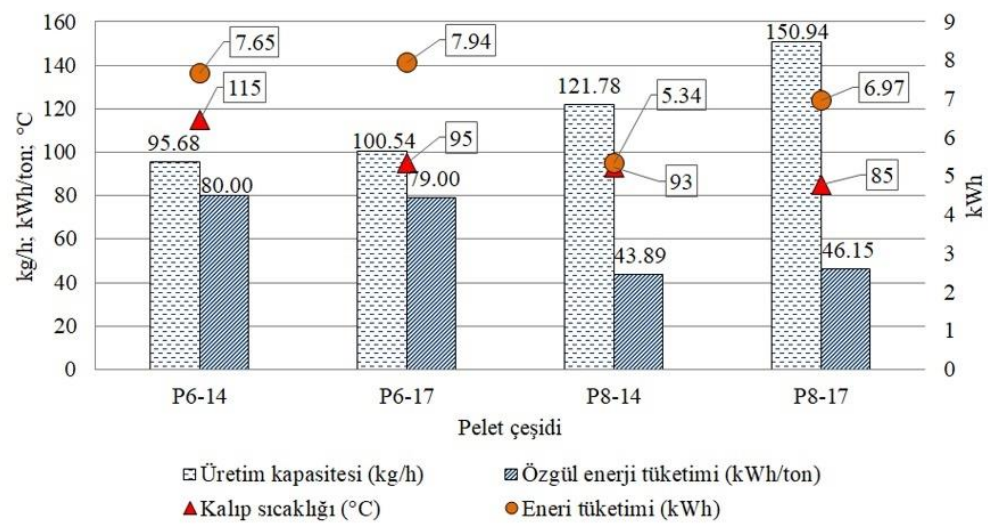

Şekil 4. Pelet üretimi sırasında üretim kapasitesi, enerji tüketimi ve kalıp sıcaklıkları

Her iki çapta üretilen peletler için, peletleme neminin artışı, pelet üretim kapasitesini arttırmıştır. Ungureanu ve ark., (2018), materyal nemindeki artışın peletleme sırasında materyalin akışkanlığını arttırarak pelet kalıbı ve sıkıştırma silindirleri arasındaki sürtünmeyi azalttığını bildirmiştir. Peletleme neminin artışı kalıp sıcaklığını ve hammaddenin pelet formu kazanması için gereken enerji ihtiyacını azaltmıştır. En düşük ve en yüksek pelet üretim kapasitesi sırasıyla, P6-14 peletlerinde $95.68 \mathrm{~kg} / \mathrm{h}$ ve P8-17 peletlerinde $150.94 \mathrm{~kg} / \mathrm{h}$ olarak hesaplanmıştır. Pelet çapının artış1 ile pelet kütle ve boyutları artarak üretim kapasitesinin artışına neden olmuştur. P8-17 peletlerinde, 1213 Amper akım değerinin sağlandığı koşullarda materyal besleme miktarının fazla oluşu üretim kapasitesini arttırmıştır. Benzer şekilde P6-17 peletlerinde saatlik enerji tüketimi değeri P6-14 peletleriyle yakın değerdedir. Yüksek nem içeriği ve materyal miktarının fazla oluşu pelet üretiminde düzensizliklere neden olarak saatlik enerji tüketimini yükseltmiş̧ir. Üretim kapasitesi ile özgül enerji tüketimi değerleri arasında negatif ilişki bulunmaktadır. Düşük nemli ve dar kesitli kalıpla üretilen P614 peletlerinde özgül enerji tüketimi $80 \mathrm{kWh} /$ ton iken geniş kesitli kalıpta, yüksek nem içeriğinde pelet üretimi sırasında $46.15 \mathrm{kWh} /$ ton özgül enerji tüketimi değeri elde edilmiştir.

Üretilen peletlerin fiziksel özellikleri Çizelge 2'te yer almaktadır. 
Çizelge 2. Çim biçme artıklarından elde edilen peletlerin fiziksel özellikleri

\begin{tabular}{lccccccc}
$\begin{array}{l}\text { Pelet } \\
\text { Çeşidi }\end{array}$ & $\begin{array}{c}\text { MC } \\
(\boldsymbol{\%})\end{array}$ & $\begin{array}{c}\mathbf{L} \\
(\mathbf{m m})\end{array}$ & $\begin{array}{c}\mathbf{D} \\
(\mathbf{m m})\end{array}$ & $\begin{array}{c}\text { BD } \\
\left(\mathbf{k g} / \mathbf{m}^{\mathbf{3}}\right)\end{array}$ & $\begin{array}{c}\text { PD } \\
\left(\mathbf{k g} / \mathbf{m}^{\mathbf{3}}\right)\end{array}$ & $\begin{array}{c}\text { PDI } \\
(\boldsymbol{\%})\end{array}$ & $\begin{array}{c}\text { IR } \\
(\boldsymbol{\%})\end{array}$ \\
\hline P6-14 & $11.63^{\mathrm{a}}$ & $14.80^{\mathrm{a}}$ & $6.29^{\mathrm{a}}$ & $624.07^{\mathrm{d}}$ & $1024.11^{\mathrm{c}}$ & $95.97^{\mathrm{a}}$ & $99.23^{\mathrm{a}}$ \\
\hline P6-17 & $15.28^{\mathrm{c}}$ & $16.98^{\mathrm{b}}$ & $6.40^{\mathrm{b}}$ & $528.49^{\mathrm{c}}$ & $871.75^{\mathrm{b}}$ & $92.33^{\mathrm{b}}$ & $97.81^{\mathrm{b}}$ \\
\hline P8-14 & $12.87^{\mathrm{b}}$ & $17.40^{\mathrm{b}}$ & $9.03^{\mathrm{c}}$ & $507.70^{\mathrm{b}}$ & $884.21^{\mathrm{b}}$ & $78.83^{\mathrm{c}}$ & $95.98^{\mathrm{c}}$ \\
\hline P8-17 & $15.24^{\mathrm{c}}$ & $20.70^{\mathrm{c}}$ & $9.24^{\mathrm{d}}$ & $479.29^{\mathrm{a}}$ & $787.06^{\mathrm{a}}$ & $84.53^{\mathrm{d}}$ & $94.12^{\mathrm{d}}$ \\
\hline Önemlilik* $^{*}$ & 0.00 & 0.00 & 0.00 & 0.00 & 0.00 & 0.00 & 0.00 \\
\hline
\end{tabular}

*Aynı sütunda farklı harfi taşıyan değerler arasındaki fark istatistiksel olarak önemlidir $(\mathrm{p}<0.05)$. MC: Nem içeriği, L: Pelet boyut, D: Pelet çapı, BD: Yığın yoğunluğu, PD: Parça yoğunluğu, PDI: Dayanıklılık direnci, IR: Darbe direnci

Varyans analizi sonuçlarına göre; peletleme nemi ve pelet çapının bütün fiziksel kalite parametreleri üzerine etkisi istatistiksel olarak önemlidir $(\mathrm{p}<0,05)$.

Çizelge 2'de görüldüğü gibi peletleme neminin artış1 6 ve $8 \mathrm{~mm}$ çapındaki peletlerin neminde artışa neden olmuştur. Peletleme işlemi sırasında kalıp sıcaklığına maruz kalan peletler bir miktar nem kaybetmişlerdir. Peletleme nemine göre en yüksek nem kaybı, düşük nem içeriği ve dar kesitli kalıptaki sıkıştırma işleminden dolayı P6-14 peletlerinde \%16 düzeyindedir. Limousy ve ark., (2013), düşük nem içeriğindeki peletlerde yüksek yanma verimi elde etmiştir. Peletlerin nem içeriği, yanma verimini etkileyen bir faktördür. Bu nedenle EN ISO 17225-6 standardında, pelet neminin A sınıfı için $\leq \% 12$, B sınıfı için $\leq \% 15$ olması gerektiğini bildirmiştir (EN ISO 17225-6, 2014). Üretilen peletlerde en düşük nem içeriğine sahip olan P6-14 peletleri EN ISO 17225-6 standardına göre A sınıfında yer alırken, diğer peletler yüksek nem içerikleri nedeniyle B sınıfındadır. Tumuluru, (2018), aynı nem içeriğinde $8 \mathrm{~mm}$ ve $10 \mathrm{~mm}$ çapında ürettiği peletlerde, $10 \mathrm{~mm}$ çapındaki pelet nemlerinin $8 \mathrm{~mm}$ çapındaki pelet nemlerine göre daha yüksek elde edildiğini bildirmiştir. Yazar bu durumun sebebini, 8 mm çapındaki kalıbın kesit alanının $10 \mathrm{~mm}$ çapındaki kalıba göre daha dar olması ve sürtünmeden kaynaklanan sıcaklık artışının pelet nemini daha hızlı buharlaştırması olarak açıklamıştır. Çalışma kapsamında elde edilen veriler, yapılan çalışmalarla paralellik göstermiştir. Kalıp deliğinin kesit alanının azalması daha fazla nem içeriğinin buharlaşmasına neden olduğundan, dar çaptaki pelet kalıplarının yüksek nem içeriğindeki peletleme işlemini tolere edebileceği sonucuna varılmıştır.

Peletleme neminin artışıyla pelet boylarında uzama ve pelet çaplarında genişleme meydana gelmiştir. $8 \mathrm{~mm}$ çapındaki peletlerin boy ve çaplarındaki genişleme daha belirgindir. EN 17225-6'da yer alan pelet çapı sınır değerlerine göre $6 \mathrm{~mm} \leq \mathrm{D} \leq 25 \mathrm{~mm} \pm 1 \mathrm{~mm}$ 'lik sapma değerinin dışına çıkılmıştır.

Peletleme nemi ve pelet çapındaki artışlar, peletlerin yığın yoğunluklarında düşüşe neden olmuştur. P6-14 peletlerinde en yüksek yığın yoğunluğu değeri olan $624.07 \mathrm{~kg} / \mathrm{m}^{3}$, pelet çapı ve peletleme neminin artmasıyla P8-17 peletlerinde $479.29 \mathrm{~kg} / \mathrm{m}^{3}$ olarak hesaplanmıştır. Nem içeriğinin ve pelet çapının artması peletleri hacimsel olarak genişleterek hacim belirleme kabında daha fazla yer kaplamasına neden olmuştur. Buna göre, nem içeriğinin ve pelet çapının artması depolama ve taşıma etkinliğini düşüren faktörler olduğu söylenebilir. EN ISO 17225-6 standarında peletlerin yığın yoğunluğunun $600 \leq \mathrm{BD}$ olması gerektiğini bildirilmiştir (EN ISO 17225-6, 2014). Çalışmada elde edilen P6-14 peletleri standart değeri taşımakta olup, yüksek nem içeriğinde ve $8 \mathrm{~mm}$ çapındaki peletler ilgili standardı karşılamamaktadır. Parça yoğunluğu değeri, peletlerin otomatik yakma sistemlerinde yüksek verimde yanma sağlanabilmesi için önemlidir (Serrano et al. 2011). Pelet parça yoğunlukları incelendiğinde, peletleme nemindeki artış, peletlerde gevşek yapı oluşturması nedeniyle parça yoğunluğu değerlerini düşürmüştür. Yapılan çalışmalarda, tarımsal endüstri artıklarının peletlenmesinde, peletleme neminin \%10'dan \%15'e çıkarılması peletlerin parça ve yığın yoğunluğunu arttırırken (Valdés et al. 2018), Mani ve ark., (2006) buğday sapı, arpa sapı, mısır koçanı ve dallı darının peletlenmesinde peletleme neminin \%12'den \%15'e çıkarılmasıyla pelet parça yoğunluğunun düştüğünü bildirmiştir. Zawiślak et al. (2020), \%18 nem içeriğinde ürettiği papatya artığ 1 ve huş ağacı talaşı peletlerinde parça yoğunluğu değerini sırasıyla $1033 \mathrm{~kg} / \mathrm{m}^{3}$ ve $1146 \mathrm{~kg} / \mathrm{m}^{3}$ 
olarak hesaplamıştır. Koçer ve Kürklü (2020), zeytin, nar ve bağ budama artıklarından üretilen peletlerin parça yoğunluklarının peletleme nemiyle ters orantılı olduğunu bildirmiştir. Çalışmada üretilen peletlerde, nem içeriği artışının yanı sıra pelet çapı artışının da parça yoğunluğunu düşüren bir etken olduğu görülmektedir. En yüksek parça yoğunluğu P6-14 peletlerinde $1024 \mathrm{~kg} / \mathrm{m}^{3}$, en düşük parça yoğunluğu P8-17 peletlerinde $787 \mathrm{~kg} / \mathrm{m}^{3}$ olarak elde edilmiştir (Çizelge 2). Üretilen peletlerin görselleri incelendiğinde, P6-14 peleti dışındakiler gevşek ve düşük dayanımlı yapısıyla dikkat çekmektedir (Şekil 3).

Üretilen çim peletlerinin pelet dayanıklılık dirençleri ve kırılma dirençleri, peletleme neminin ve pelet çapının artışıyla düşüş göstermiştir. Dayanıklılık direnci ve darbe direnci test sonrası pelet görünümleri Şekil 5'de yer almaktadır.

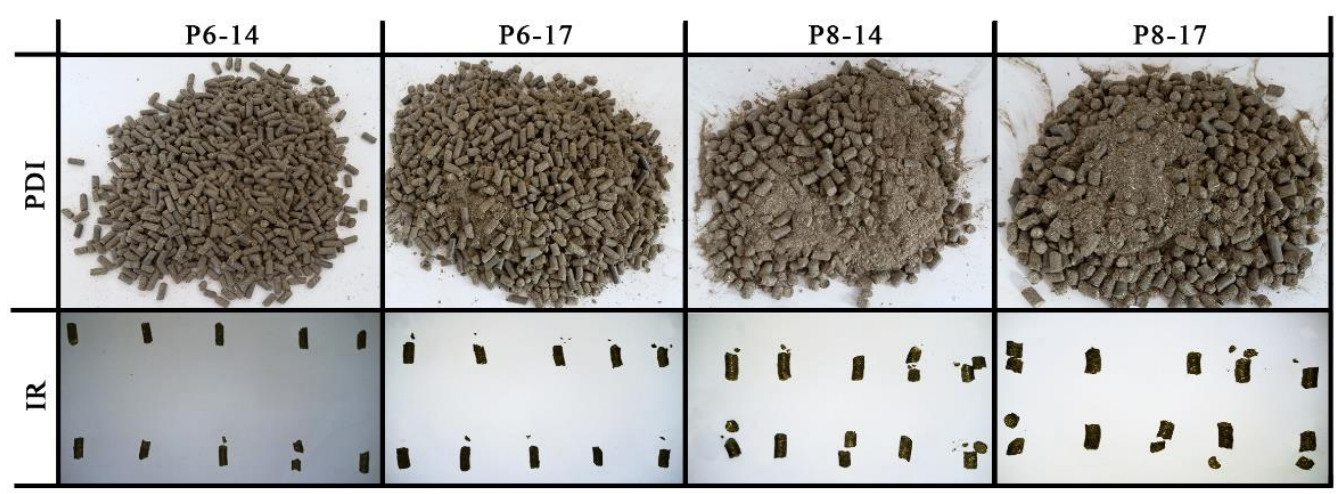

Şekil 5. Çim peletlerinin dayanıklılık direnci (PDI) ve darbe direnci (IR) test sonrası görünümleri

Yüksek nem içeriği ve pelet çapının artması peletin silindirik ve yoğun yapısının bozulmasına neden olarak partiküllerin bir arada tutunmasını engellemiştir. Dayanıklılık direnci testi sonrasında peletler ufalanarak toz haline gelmiştir. En yüksek dayanım \%95.97 ile P6-14 peletlerinde, en düşük dayanım \%78.83 ile P8-14 peletlerinde tespit edilmiştir. EN ISO 17225-6 standardında pelet dayanıklılık direnci sınır değerleri A sınıfı için $\geq \% 97.5$, B sınıfı için $\geq \% 96$ olarak belirlenmiştir (EN ISO 17225-6, 2014). Çalışma kapsamında üretilen peletler ilgili standarda göre standart sınıflarında yer almamaktadır. Peletleme nemindeki artış hammadde çeşidine bağlı olarak pelet dayanıklılığına farklı düzeylerde etki edebilmektedir. Theerarattananoon ve ark., (2011), materyal nem içeriğinin $\% 10$ 'dan \%16'ya arttırılmasıyla buğday ve mısır saplarında dayanıklılık direnci azalırken, sorgum saplarında dayanıklılık direncinin arttığını bildirmiştir. Harun ve Afzal, (2015) sert ve granüler yapıdaki odunsu materyal ile otsu yapıdaki tarımsal artıkların değişken oranlardaki karışımlarından pelet üretmiştir. Karışım içerisinde otsu biyokütle oranının artmasıyla peleti oluşturan partiküllerin yapışkanlık özelliğinin arttı̆̆ını ve peletlerin daha kolay üretilerek fiziksel açıdan daha dayanıklı yapıda olduğunu bildirmiştir. Tumuluru (2018), aynı nem içeriğinde üretilen buğday samanı, çam ve ardıç peletlerinde pelet çapı artışının peletlerin dayanıklılık direncini düşürdüğü sonucuna varmıştır. Birçok biyokütle kaynağı için ideal düzeyde olan \%14 nem içeriğinin, tamamen otsu yapıda olan çim biçme artıkları için yüksek nem sınıfına dahil olduğu sonucuna varılmıştır.

Darbe direnci testinde peletleme nem içeriğinin artışı peletlerin kırılmaya karşı gösterdiği direnci düşürmüş̧ür. Peletleme neminin \%14 düzeyinde olması, genellikle peletlerin uçlarında kırılmalara neden olmuştur. Nem içeriğinin ve pelet çapının atmasıyla peletler sıkışık ve yoğun formlarını yitirmeye başladığı için $8 \mathrm{~mm}$ çapındaki peletlerde uç noktalardan kırılma ile birlikte bölünmeler de meydana gelmiştir. Yapılan çalışmalarda yüksek parça yoğunluğuna sahip (1200-1250 $\mathrm{kg} / \mathrm{m}^{3}$ ) peletlerin kırılma dirençlerinin \%99.9 düzeyinde oldukça dayanıklı yapıda olduğu bildirilmiştir (Biswas et al. 2011). Theerarattananoon et al., (2011), pelet kırılma dirençlerini yüksek (IR $\geq \% 80$ ), orta $(70 \geq I R \geq 80)$ ve düşük kaliteli $(I R \leq \% 70)$ olarak sınıflandırmıştır. Bu sınıflandırmaya göre çalışmada üretilen peletler yüksek kaliteli sınıfına girmesine rağmen diğer fiziksel parametrelerde \%14-17 peletleme neminde ve 6-8 mm pelet çapında üretilen çim peletlerinin oldukça düşük kalitede olduğu görülmektedir. Ayrıca, uzun peletlerin kısa peletlere göre kırılmaya daha yatkın olduğu araştırmacılar tarafından bildirilmiştir (Tarasov et al. 2013; Said et al. 2015). Çalışmada elde edilen 
verilere göre, artan peletleme nemi ve pelet çapında pelet boyları artış göstererek daha kırılgan yapıya sahip olmuşlardır.

\section{Sonuç}

Çalışmada peyzaj alanlarından çıkan çim biçme artıkları \%14 ve \%17 nem içeriğinde peletlenerek 6 ve $8 \mathrm{~mm}$ çapında peletler elde edilmiştir. Pelet üretimi sırasında enerji tüketim değerleri ve üretim kapasitesi, pelet üretimi sonrasında pelet fiziksel özellikleri test edilmiştir. Peletleme neminin artışı çim peletlerinin fiziksel kalitelerine negatif yönde etki etmiş olup, düşük yoğunluklu ve dayanıksız peletler üretilmesine neden olmuştur. Aynı nem düzeyindeki $6 \mathrm{~mm}$ çapındaki peletler 8 $\mathrm{mm}$ çapındaki peletlere göre daha dayanıklı ve fiziksel açıdan daha stabil yapıdadır. Pelet kalıbı çapının daralması, pelet üretimi sırasında sürtünmeyi arttırarak kalıp sıcaklığının artışına neden olmuş ve daha yoğun formda peletler elde edilmiştir. Üretilen peletlerden $6 \mathrm{~mm}$ çap ve \%14 peletleme nemindeki peletlerin nem içeriği, çap ve yığın yoğunluğu değerleri EN ISO 17225-6 standartlarını sağlamıştır. Çap değerlerindeki $1 \mathrm{~mm}$ 'den fazla sapma nedeniyle $8 \mathrm{~mm}$ çapındaki peletler standart dışı kalmıştır. Pelet depolama etkinliğinin önemli bir göstergesi olan yığın yoğunluğu değeri EN ISO $17225-6$ standardına göre sadece $6 \mathrm{~mm}$ çap ve \%14 nem içeriğinde üretilen peletlerde sağlanmıştır. Fakat tüm peletlerin dayanıklılık direnci değeri standart değerin altında kalmıştır.

Çim materyali yüksek nem içeriğine gerek olmaksızın yüksek yoğunlukta sıkıştırılabilecek otsu bir biyokütle kaynağıdır. Bu kapsamda, daha kaliteli peletlerin elde edilmesine yönelik, çim artıklarının daha düşük nem düzeyinde peletlenmesi ilgili çalışmaların yapılması önerilir.

Odunsu, daha iri partikül boyutlarında, peletlenmesi için yüksek sıkıştırma gücü gereken diğer biyokütle kaynaklarının peletlenmesinde, çim materyalinin karışım materyali olarak kullanılmasının peletleme işleminde bağlayıcı etki sağlayacağı öngörülmektedir.

\section{Kaynaklar}

Adapa, P., Tabil, L., Schoenau, G., 2009. Compaction characteristics of barley, canola, oat and wheat straw. Biosystems Engineering. 104:335-344.

Agar, D.A., Rudolfsson, M., Kalén, G., Campargue, M., Da Silva Perez, D., Larsson, S.H., 2018. A systematic study of ring-die pellet production from forest and agricultural biomass. Fuel Processing Technology. 180:47-55.

Aghayev, E., 2019. Investigation of pretreatment methods to improve biogas yıeld of agricultural wastes. Hacettepe Üniversitesi,Fen Biilimleri Enstitüsü,Doktora Tezi,Ankara 186.

Amiri, H., Kianmehr, M.H., Arabhosseini, A., 2019. Effect of particle size, die rotary speed and amount of urea on physical properties of the produced pellet. International Journal of Environmental Science and Technology. 16:2059-2068.

Anonim(a), http://www.milagri.it/index.php?option=com_content\&view=article\&id=70\&Itemid=537\&lang=en. Erişim 5 Ocak 2021

Anonim(b), 2021. https://www.heatit.ee/en/premium-pellets. Erişim 5 Ocak 2021

Anonim(c), 2021. https://www.lanordica-extraflame.com/en/products/pellet-stoves. Erişim 5 Ocak 2021

Anonim(d), 2021.. http://termodinamik.com.ua/files/PELLET STOVE HYBRID.PDF. Erişim 5 Ocak 2021

Anonim(e), 2021. http://www.uniclass.it/wp-content/uploads/2019/01/Manual-AUDAX-LASIAN-STOVE83119L-01_EN_Sept16.pdf. Erişim 5 Ocak 2021

Anonim(f), 2021. http://www.red365.it/en/p280-erica.html. Erişim 5 Ocak 2021

ASAE, 2001. S269.4: In Cubes, Pellets, and Crumbles-Definitions and Methods for Determining Density, Durability, and Moisture Content.

ASAE S319.3, 2003. Methods for determining and expressing fineness of feed materials by sieving. 2008:S319.2

ASTM E871-82, 2019. Standard test method for moisture analysis of particulate wood fuels. West Conshohocken, PA.

Azócar, L., Hermosilla, N., Gay, A., Rocha, S., Díaz, J., Jara, P., 2019. Brown pellet production using wheat straw from southern cities in Chile. Fuel. 237:823-832.

Biswas, A.K., Yang, W., Blasiak, W., 2011. Steam pretreatment of Salix to upgrade biomass fuel for wood pellet production. Fuel Processing Technology. 92:1711-1717.

Carroll, J.P., Finnan, J., 2012. Physical and chemical properties of pellets from energy crops and cereal straws. Biosystems Engineering. 112:151-159.

Chandrasekaran, S.R., Hopke, P.K., Hurlbut, A., Newtown, M., 2013. Characterization of emissions from grass pellet combustion. Energy and Fuels. 27:5298-5306. 
Diken, B., 2017. Çim peletinin gazlaştırma performansının sapatnması üzerine bir araştırma. namık kemal üniversitesi.

Emami, S., Tabil, L.G., Adapa, P., George, E., Tilay, A., Dalai, A., Drisdelle, M., Ketabi, L., 2014. Effect of fuel additives on agricultural straw pellet quality. International Journal of Agricultural and Biological Engineering. 7:92-100.

EN 15103, 2009. Solid biofuels - Determination of bulk density. CEN/TS. London, EN: CEN.

EN 15210-1, 2009. Solid biofuels - Determination of mechanical durability of pellets and briquettes - Part 1: Pellets. CEN/TS. London, EN: CEN.

EN ISO 17225-6, 2014. Solid Biofuels Fuel Specifications and Classes. Part 6: Graded Non-Woody Pellets. Ireland, UK.

ENplus, 2015. Pellet Quality Requirements. Place du Champ de Mars 21050 Brussels, Belgium.

Filbakk, T., Jirjis, R., Nurmi, J., Høibø, O., 2011 The effect of bark content on quality parameters of Scots pine (Pinus sylvestris L.) pellets. Biomass and Bioenergy. 35:3342-3349.

Garcia-Maraver, A., Rodriguez, M.L., Serrano-Bernardo, F., Diaz, L.F., Zamorano, M., 2015. Factors affecting the quality of pellets made from residual biomass of olive trees. Fuel Processing Technology. 129:1-7.

Harun, N.Y., Afzal, M.T., 2015. Chemical and mechanical properties of pellets made from agricultural and woody biomass blends. Transactions of the ASABE. 58:921-930.

Hiloidhari, M., Das, D., Baruah, D.C., 2014. Bioenergy potential from crop residue biomass in India. Renewable and Sustainable Energy Reviews. 32:504-512.

Kaliyan, N., Vance Morey, R, 2009. Factors affecting strength and durability of densified biomass products. Biomass and Bioenergy. 33:337-359.

Kirsten, C., Lenz, V., Schröder, H.W., Repke, J.U., 2016. Hay pellets - The influence of particle size reduction on their physical-mechanical quality and energy demand during production. Fuel Processing Technology. 148:163-174.

Koçer, A., Kürklü, A., 2020. Environmental Effects Production of pellets from pruning residues and determination of pelleting physical properties. Energy Sources, Part A: Recovery, Utilization, and Environmental Effects 00:1-13.

Limousy, L., Jeguirim, M., Dutournié, P., Kraiem, N., Lajili, M., Said, R., 2013. Gaseous products and particulate matter emissions of biomass residential boiler fired with spent coffee grounds pellets. Fuel. n107:323-329.

Mani, S., Tabil, L.G., Sokhansanj, S., 2006. Effects of compressive force, particle size and moisture content on mechanical properties of biomass pellets from grasses. Biomass and Bioenergy. 30:648-654.

Niedziółka, I., Szpryngiel, M., Kachel-Jakubowska, M., Kraszkiewicz, A., Zawiślak, K., Sobczak, P., Nadulski, R., 2015. Assessment of the energetic and mechanical properties of pellets produced from agricultural biomass. Renewable Energy. 76:312-317.

Orçun, E., 1979. Özel Bahçe Mimarisi. Ege Üniversitesi Ziraat Fakültesi Yayınları, Ege Üniversitesi No152, $106 \mathrm{~s}$, İzmir.

Platace, R., Adamovics, A., Ivanovs, S., Gulbe, I., 2017. Assessment of ash melting temperature of Birch and grass biomass Pellet mixtures. Engineering for Rural Development. 16:103-107.

Pradhan, P., Mahajani, S.M., Arora, A., 2018. Production and utilization of fuel pellets from biomass: A review. Fuel Processing Technology. 181:215-232.

Said, N., Abdel Daiem, M.M., García-Maraver, A., Zamorano, M., 2015. Influence of densification parameters on quality properties of rice straw pellets. Fuel Processing Technology. 138:56-64.

Serrano, C., Monedero, E., Lapuerta, M., Portero, H., 2011. Effect of moisture content, particle size and pine addition on quality parameters of barley straw pellets. Fuel Processing Technology. 92:699-706.

Tarasov, D., Shahi, C., Leitch, M., 2013. Effect of Additives on Wood Pellet Physical and Thermal Characteristics: A Review. ISRN Forestry. 2013:1-6.

Theerarattananoon, K., Xu, F., Wilson, J., Ballard, R., Mckinney, L., Staggenborg, S., Vadlani, P., Pei, Z.J., Wang, D., 2011. Physical properties of pellets made from sorghum stalk, corn stover, wheat straw, and big bluestem. Industrial Crops and Products. 33:325-332.

Tumuluru, J.S., 2014. Effect of process variables on the density and durability of the pellets made from high moisture corn stover. Biosystems Engineering. 119:44-57.

Tumuluru, J.S., 2018. Effect of pellet die diameter on density and durability of pellets made from high moisture woody and herbaceous biomass. Carbon Resources Conversion. 1:44-54.

Ungureanu, N., Vladut, V., Voicu, G., Dinca, M.N., Zabava, B.S., 2018. Influence of biomass moisture content on pellet properties - Review. Engineering for Rural Development. 17:1876-1883.

Valdés, C.F., Marrugo, G., Chejne, F., Cogollo, K., Vallejos, D., 2018. Pelletization of Agroindustrial Biomasses from the Tropics as an Energy Resource: Implications of Pellet Quality. Energy and Fuels. 32:11489-

Wongsiriamnuay, T., Tippayawong, N., 2015. Effect of densification parameters on the properties of maize 
ÇOMÜ Zir. Fak. Derg. (COMU J. Agric. Fac.)

2021: 9 (1): 47-56

ISSN: 2147-8384 / e-ISSN: 2564-6826

doi: 10.33202/comuagri.865091

residue pellets. Biosystems Engineering. 139:111-120.

Yılmaz, H., Topakcı, M., Karayel, D., Çanakc1, M., 2020. Comparison of the physical properties of cotton and sesame stalk pellets produced at different moisture contents and combustion of the finest pellets. Energy Sources, Part A: Recovery, Utilization, and Environmental Effects.

Zawiślak, K., Sobczak, P., Kraszkiewicz, A., Niedziółka, I., Parafiniuk, S., Kuna-Broniowska, I., Tanaś, W., Żukiewicz-Sobczak, W., Obidziński, S., 2020. The use of lignocellulosic waste in the production of pellets for energy purposes. Renewable Energy. 145:997-1003. 